\title{
144. The Glutathione Contents of Malignant Tumors, Especially the Rous Chicken Sarcoma.
}

\author{
By Hidetake Yaor and Waro Nakahara.
}

(From the Government Institute for Infectious Diseases, Tokyo).

(Rec. September 21 1926. Comm. by K. MIURA, M.I.A., Oct. 12, 1926)

\section{Introduction.}

Although glutathione, the autoxidizable substance occurring in practically all living plants and animals, has been isolated and identified comparatively recently (Hopkins ${ }^{(1)}, 1921$ ), its fundamental importance in the process of oxidation and and reduction in living cells secms to be generally ascepted. It is stated that reduced glutathione (-SH-) can take up molecular oxygen, while the oxidized form (-S-S-) so produced can act as hydrogen acceptor and so catalyzes oxidation reaction.

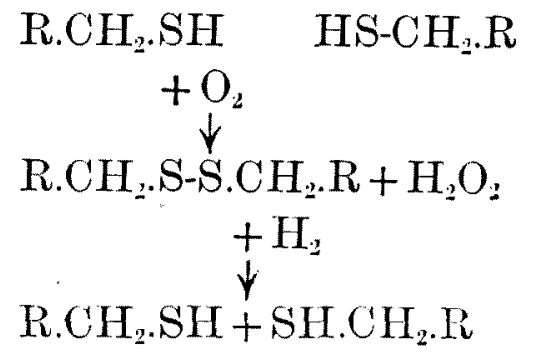

These facts are believed by Hopkins and others to have a most important and direct bearing upon the respiratory mechanism of living tissues.

In 1908 Heffter $^{(2)}$ examined the distribution in various organs of the substances containing the sulphydril group by means of the sodium nitroprusside reaction. This work was followed by that of Arnold ${ }^{(3)}$ who tested the nitroprusside reaction of organ extracts in acidified $\mathrm{Na}_{-} \mathrm{SO}_{4}$ or $\left(\mathrm{NH}_{4}\right)_{2} \mathrm{SO}_{4}$ solution. $\mathrm{He}$ was able to detect nitroprusside responsible substances in all the organs tested, though the intensity of the reaction varied considerably according to different organs. He also proved that this nitroprusside responsible substance is no other than cystein. Later investigators showed that $H$ of $S H$ group contained in cystein is in labile combination, and therefore, with the cooperation of an ex- 
ceedingly minute amount of metalic catalyzer, it manifosts a powerful reducing action (Mathews and Walker ${ }^{(4)}$, Sakuma(5)). The well known reducing power of fresh tissue may therefore depend on the labile hydrogen of sulphydril group (Strassner ${ }^{(6)}$ ). As a matter of fuct Hopkins(1), who isolated and identified the sulphydril group of tissues under the name of glutathione, believes that the respiratory mechanism of tissues is explainable on the basis of this autoxidizable substance.

The point which particularly attracted our attention was the apparent general rule that the tissues especially active metabolically show distinctly strong reaction of cystein, as may be gathered from the data given by Heffter ${ }^{(2)}$, Arnold( ${ }^{(3)}$, etc. Abderhalden and Wertheimer ${ }^{(7)}$ also noted that rapilly growing tissues usually showed especially strong nitroprusside reaction. On the other hand, the reduced vitality of a tissue was shown to be accompanied by a corresponding decrease of the nitroprusside reaction, as in the case of cornea $\left(\operatorname{Reis}^{(8)}\right.$, Goldschmidt ${ }^{(9)}$, Jess $\left.^{(10)}\right)$ and of hair-root (Kaye $\left.{ }^{(1)}\right)$.

With these facts on hand the relations of glutathione in malignant tumors would seem to be of special interest. So far as we are aware, no information on this point is available in literature with the exception of a sentence or so in one of Hopkin's publications"). This author made a bare statement to the effect that the glutathione content of cancer tissue is surprizingly small, giving no further details. We have, therefore, proposed to ourselves the task of investigating the glutathione contents of some animal tumors, and our results are given in the prosent paper. Among the tumor's tested were Flexner-Jobling rat carcinoma, Fujinawa rat sarcoma, and Bashford mouse carcinoma, but we studied particulaly the Rous chicken sarcoma No. 1, which is the most malignint and rapidly growing of all these tumors, and which distinguishes itself by being resistant to desiccation, as one of us (Nakaliara $\left.{ }^{(12)}\right)$ has previously shown.

\section{Experiment 1.}

Method.-The animals were anaesthetized with chloroform and bled to death from the jugular vein. The tumor or other tissues required were removed and weighed instantly. 5 grams of each tissue was then immediately ground fine with sand in $20 \mathrm{cc}$ of $10 \%$ solution of trichloro-acetic acid. The tissue emulsion was centrifuged at the speed of about 6000 revolutions jer minute and the clear supernatant fluid (extract) was then transferred to a tost tube. 
The extract so prepared was divided into two equal portions. One of these was retained as control, while to the other portion was added a few drous of $5 \%$ sodium nitroprusside. The reaction of this mixture was then brought to the neutral point with $\mathrm{NaOH}$, and the intensity of the purplish-red color developing at this moment was noted as indicaling the relative amount of the nitroprusiside responsible substance present. The results of this experiment are shown in Table I.

\section{Taible I.}

Nitroprusside Responsible Substances in Tumors and Normal 'Tissues.

(I)

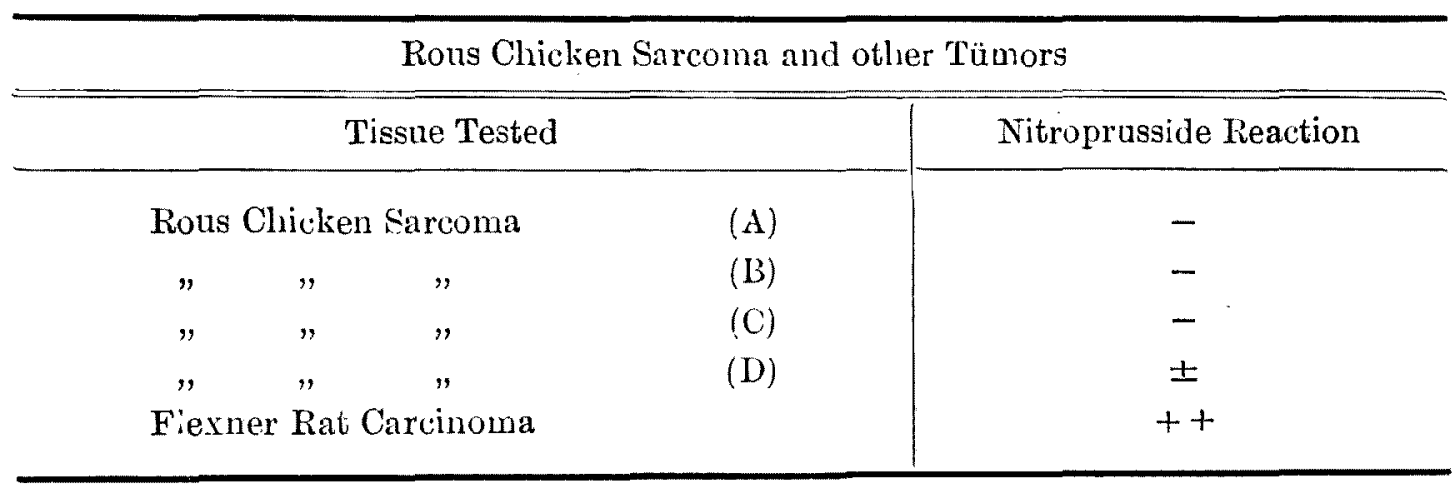

(II)

\begin{tabular}{cc|c}
\hline \multicolumn{2}{c}{ Normal Tissues } \\
\hline \multicolumn{2}{c|}{ Tissue Tested } & Nitroprusside Reaction \\
\hline Chicken Muscle (Skeletal) & (A) & + \\
" " & (B) & + \\
Rat Muscle (Skeletal) & & + \\
Chicken Testicle & (A) & +++ \\
" $"$ & (B) & +++ \\
Rat Testicle & & +++ \\
Chicken Spleen & & ++ \\
Chicken Liver & & + \\
Chicken Brain & & +
\end{tabular}

The data presented in the above table indicate unmistakably that the Rous chicken sarcoma is very characteristic in showing no or exceodingly feeble response to the nitroprusside test. This tumor is in this way readily separable from other malighant tumors as well as from 
normal tissue, while there appears to be no gencrally applicable difference in the reaction betweon the tumor and normal tissues.

It is well worthy of comment that the Rous sarcoma shows so negligible a reaction, as it is practically impossible to obtain for test a piece of this sarcoma entirely free from blood, blood vessels, etc., which are expected to contain the nitroprusside responsible substance.

\section{Experiment 2.}

The above experiment was repeated by means of the color reaction employed by Arnold, among others, for the detection of the sulphydril group in tissues, and by Hopkins for his glutathione.

Method-10 grams of tissues were ground in the mortar with sand and extracted with $20 \mathrm{ce}$ of saturated ammonium sulphate solution, which was acidified with $\mathrm{SO}_{4} \mathrm{H}_{2}$. This was done immediately after the tissues were removed from the animals freshly bled to death. The tissue emulsion was centrifuged and the clear supernatant fluid tested by adding to it a few drops of $5 \%$ sodium nitroprusside solution and ammonia. The reaction was judged by the intensity of the developing color. Table. II represents the results.

\section{Table II.}

Nitroprusside Responsible Substances in Tumors and Normal Tissues.

(I)

Rous Chicken Sarcoma and other Tumors.

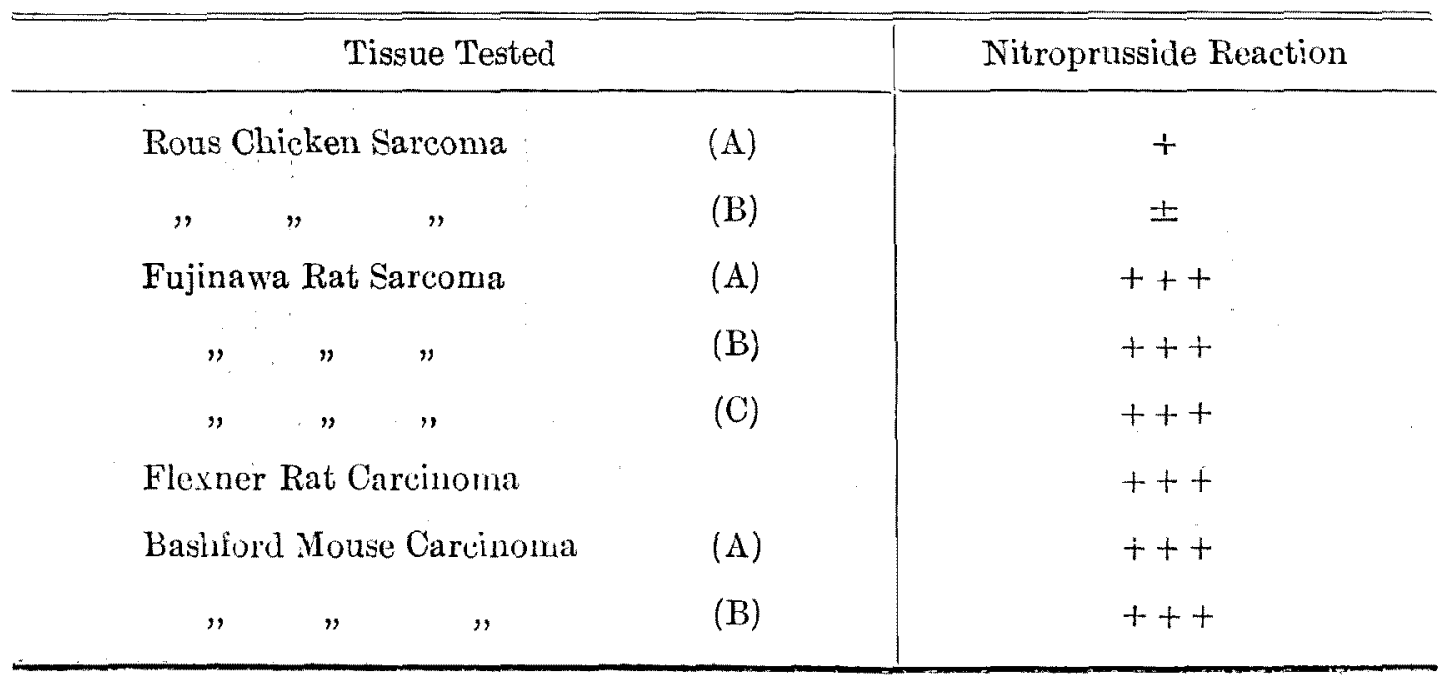


(II)

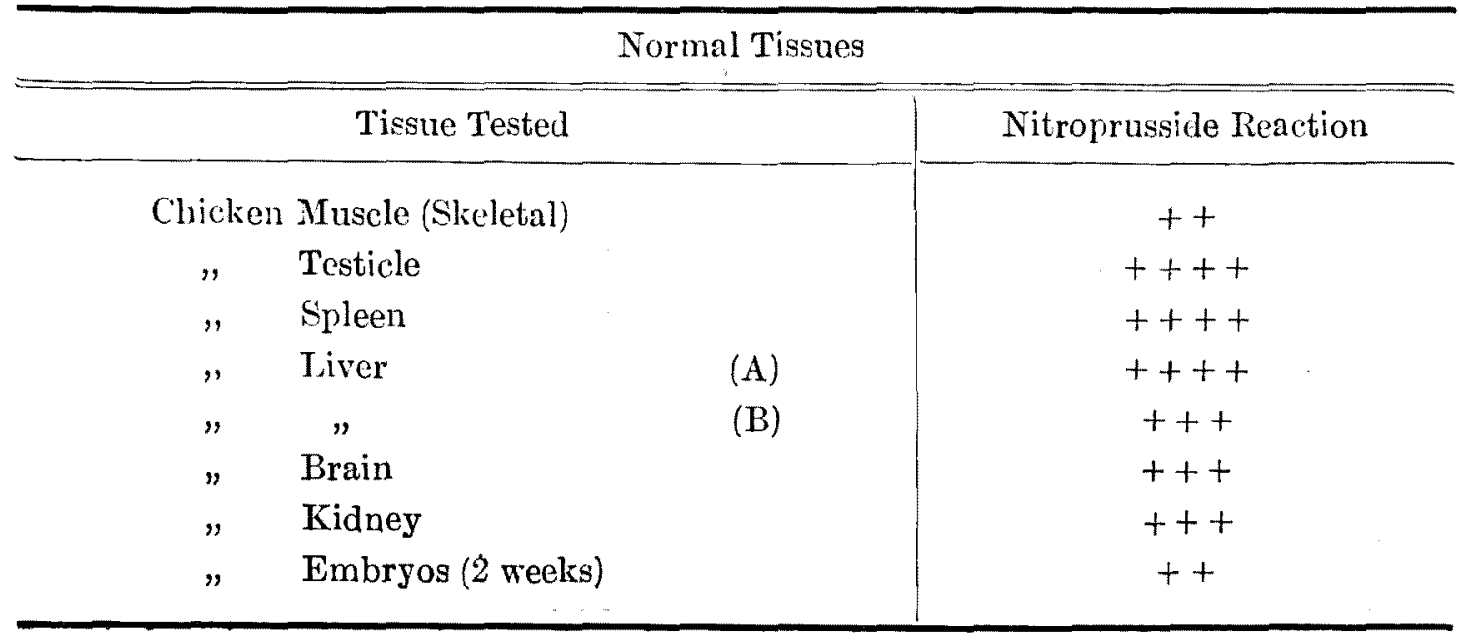

The reaction of the Rous sarcoma is only weakly positive, and is quite strikingly different from those of other tissues, normal as well as malignant.

\section{Experiment 3.}

We believe the results of the two proceeding experiments to be sufficient for the comparison of the sulphydril group or glutathione contents of tissues. However, considering the fact that certain other substances beside glutathione are capable of responding to the sodium nitroprusside test, we have carried out an additional experiment with the method of Tunnicliffe ${ }^{(13)}$, in order to make quantitative estimations. Needless to say that this method offers a more accurate comparison than the two previous procedures. This method is not interfered with by the presence of such substances as urea, uric acid, creatinine, glucose, or fructose.

Method.-The weighed amount of freshly taken tissue was extracted with $10 \%$ trichloro-acetic acid solution as in Experiment 1 , but the process of extraction was repeated twice, in order to remove all the soluble sulphydril groups of the tissue. We found that a third extraction was unnecessary for this purpose.

The clear extract obtained was titrated with N/100 iodine solution, using starch instead of sodium nitroprusside as indicator.

From the equation

$2 \mathrm{R} . \mathrm{SH}+\mathrm{I}_{2}=\mathrm{R} . \mathrm{S} . \mathrm{S} . \mathrm{R}+2 \mathrm{HI}$,

1 cc. $\mathrm{N} / 100 \mathrm{I}_{2}=2.5 \mathrm{mg}$. reduced glutathione.

The results are recorded in Table III. 
Table III.

Glutathione Contents of Tumors and Normal Tissues.

(I)

Rous Chicken Sarcoma and Other Tumors.

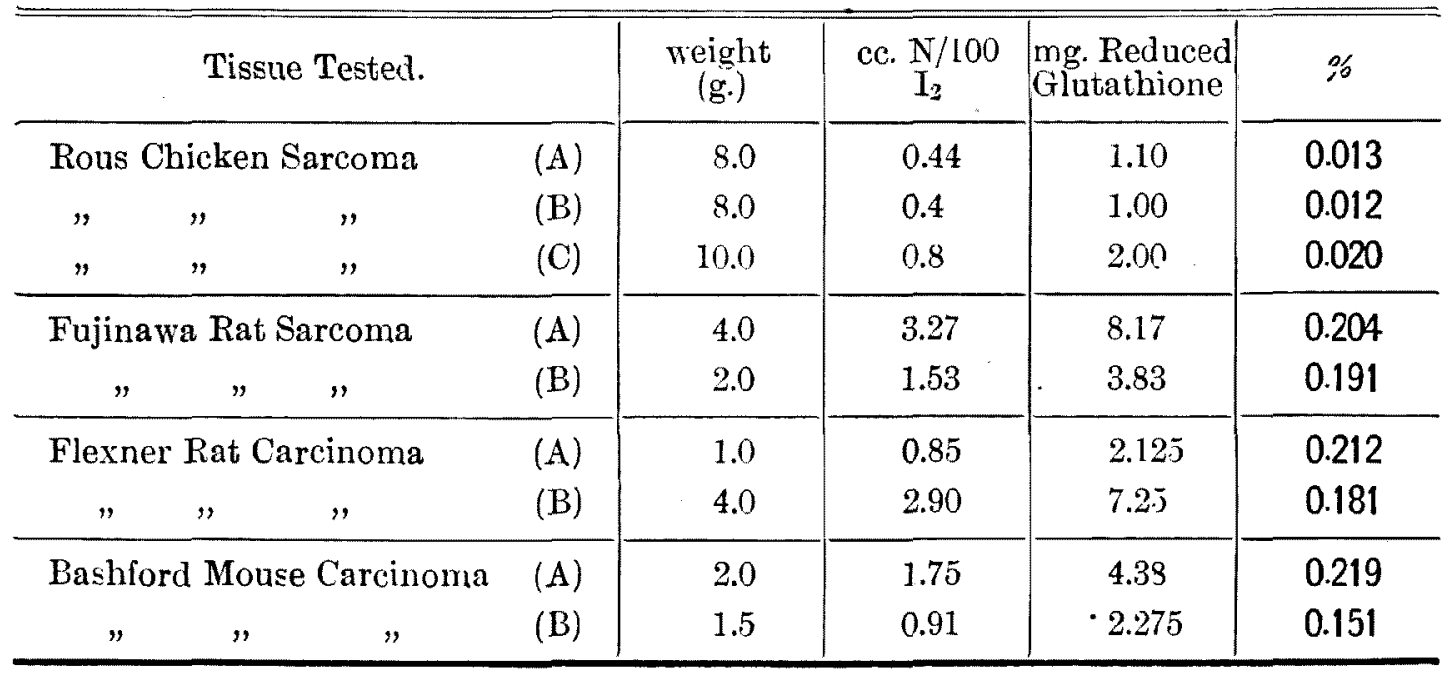

(II)

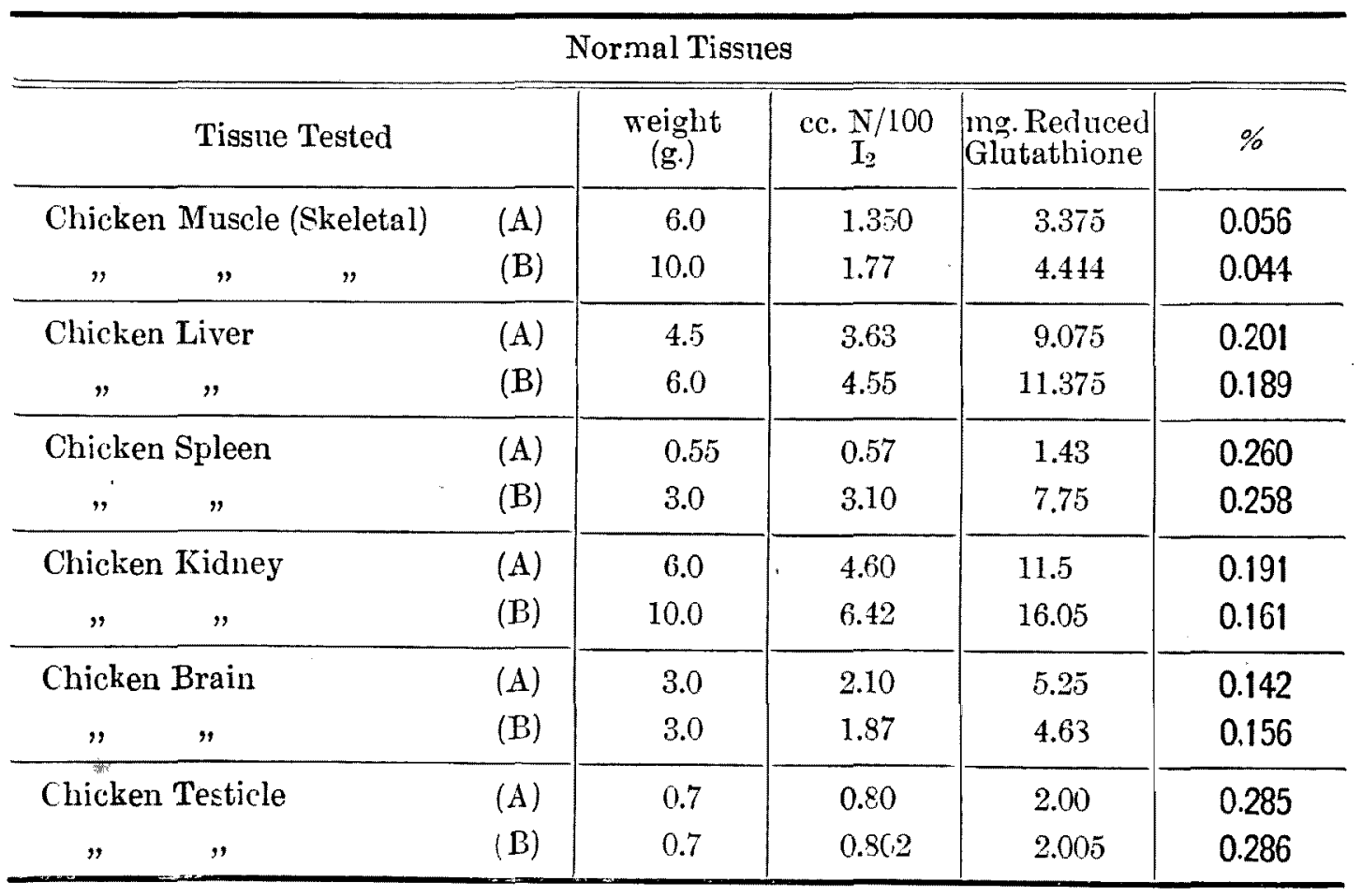

The above quantitative estimations collaborate the findings of Experiments I and II, and show that the Rous sarcoma alone gives a distinctly low figure. Our percentages for normal tissues agree fairly well with those reported by Tumnicliffe. 


\section{Discussion.}

From what has been known concerning the distribution of glutathione in various animal tissues it may be expected that the rapidly growing tissues, such as maliginant tumors, may contain a largo amount of this substance. Our results, howerer, are somewhat contradictory to this expectation and some normal tissues responded more encrgetically to the nitroprusside test than did mammalian malignant tumor's. The point which seems to be of altogether exceptional interest is that the Rous chicken sarcoma, which is by far the most rapidly growing of all the tumors tested, contains an exceedingly minute amount of glutathione.

The metabolism of the Rous sareoma has been studied by Murphy and Hawkins ${ }^{(14)}$, following the method of Warburg, and they found no material difference between this tunor and the Flexner-Jobling rat carcinoma as regards the rate of respiration and of glycolysis. Since we found an overwhelming discrepancy in the glutathion content of the avian and mammalian tumors, it is not unreasonable to suspect that the Rous sarcoma may be quite different from other tissues in its respiratory mechanism. If that is the case we might in that way be able to account for the extraordinary resistance to desiccation and to glycerination, which is possessed by the Rous sarcoma and is not manifested by the mammalian tumors. While no definite conclusion can be justitied on the basis of the limited knowledge on the subject, we feel that this possibility is of sufficient interest to be especially pointed out.

\section{Summary.}

Glutathione, the autoxidizable substance of fundamental importance in the respiration of almost all the living cells, is found in the Rous chicken sarcoma in a negligible quantity, while the same substance is present in abundance in other malignant tumors and normal tissues. It is of interest to note that the Rous sarcona is milque in its ability to withstand desiccation. The comnection between the practical absence of glutathione and the resistance to desiecation, while it cannot be definitely established, would seem highly probable.

(We wish to express our thanks to Mr. S. Yoshikawa for his technical assistance). 


\section{Literature Cited.}

1. Hopkins, F. G. Biochem. Jour. Vol. 15, 286, 1921.

2. Heffter, A. Mediz.- naturwiss. Arch., Bd. 1, 81, 1908.

3. Arnold, V. Zeit. f. physiol. Chem., Bd. 70, 314, 1911.

4. Mathews and Walker Jour. Biol. Chem., vol. 6, 29, 1909.

5. Sakuma, S. Biochem. Zeit., Bd. 142, 68, 1923,

6. Strassner, W. Biochem. Zeit., Bd. 29, 295, 1910.

7. Abderhalden, E. und Wertheimer, E. Pfïgers Archiv., Bd. 197. 131, 1922.

8. Reis, V. Arch. f. Ophthalmol., Bd. 80, 588, 1912.

9. Goldschmidt, M. Arch. f. Ophthalmol., Bd. 93, 447, 1917.

10. Jess, A. Zeit. f. physiol. Chem., Bd. 110, 266, 1920.

11. Kaye, M. Biochem. Jour., vol. 18, 1289, 1924.

12. Nakahara, W. Gann, Japan. Jour. Cancer Research, vol. 20, 13, 1926.

13. Tunnicliffe, H. E. Biochem. Jour., vol. 19, 194, 1925.

14. Murphy, J. B., and Hawkins, J. A. Jour. General Physiol., vol. 8, 115, 1925. 